\title{
California Central Valley Summer Heat Waves Form Two Ways*
}

\author{
YUN-YOUNG LEE \\ Department of Land, Air and Water Resources, University of California, Davis, Davis, California, \\ and Climate Research Department, APEC Climate Center, Busan, South Korea \\ RICHARD GROTJAHN \\ Department of Land, Air and Water Resources, University of California, Davis, Davis, California
}

(Manuscript received 17 April 2015, in final form 10 November 2015)

\begin{abstract}
California Central Valley (CCV) heat waves are grouped into two types based on the temporal and spatial evolution of the large-scale meteorological patterns (LSMPs) prior to onset. The $k$-means clustering of key features in the anomalous temperature and zonal wind identifies the two groups. Composite analyses show different evolution prior to developing a similar ridge-trough-ridge pattern spanning the North Pacific at the onset of CCV hot spells. Backward trajectories show adiabatic heating of air enhanced by anomalous sinking plus horizontal advection as the main mechanisms to create hot lower-tropospheric air just off the Northern California coast, although the paths differ between clusters.

The first cluster develops the ridge at the west coast on the day before onset, consistent with wave activity flux traveling across the North Pacific. Air parcels that arrive at the maximum temperature anomaly (just off the Northern California coast) tend to travel a long distance across the Pacific from the west. The second cluster has the ridge in place for several days prior to extreme CCV heat, but this ridge is located farther north, with heat anomaly over the northwestern United States. This ridge expands south as air parcels at midtropospheric levels descend from the northwest while lower-level parcels over land tend to bring hot air from directions ranging from the hot area to the northeast to the desert areas to the southeast. These two types reveal unexpected dynamical complexity, hint at different remote associations, and expand the assessment needed of climate models' simulations of these heat waves.
\end{abstract}

\section{Introduction}

Temperature extremes have large impacts on the economy and human safety. A statistically significant increasing trend of about $5 \%$ per year in the frequency of billion-dollar disasters is reported in annual aggregates of weather and climate disasters (Smith and Katz 2013). Among them, the adjusted damages related to heat waves and drought total approximately $\$ 210$ billion for the 1980-2011 period. Heat waves also cause a large annual number of fatalities (123) on average for the

\footnotetext{
* Supplemental information related to this paper is available at the Journals Online website: http://dx.doi.org/10.1175/JCLI-D-150270.s1.

Corresponding author address: Yun-Young Lee, APEC Climate Center, 12 Centum 7-ro, Haeundae-gu, Busan 48058, South Korea. E-mail: dolkong400@gmail.com
}

period of 2004-13 in the United States (http://www.nws. noaa.gov/om/hazstats.shtml). There are considerable impacts of heat on morbidity as well. For instance, hospital admissions in Kansas City increased by $5 \%$ during the 1980 heat wave event (Jones et al. 1982).

The California Central Valley (CCV) produces half of the nation's tree fruit and nut crops by both weight and gate receipts. Fruit quality and production can be degraded by hot spells, which causes economic losses to farmers. In addition, the southern CCV has extensive dairy production, and extreme heat reduces milk production and cow fertility while raising cow morbidity and mortality. For example, the CCV dairy industry had approximately $\$ 1$ billion of economic losses from the 2006 heat wave (Bilby et al. 2008). Since the CCV has 8 of the nation's top 10 most agriculturally productive counties, understanding extreme hot weather over the CCV has great economic and social importance. 
Temperature extremes have been linked to some large-scale teleconnection patterns since such largescale wave patterns can redistribute air masses having different temperatures. Particularly during winter, temperature extremes are modulated by the PacificNorth American (PNA) pattern, North Atlantic (or Arctic) Oscillation (NAO or AO), and blocking patterns (Walsh et al. 2001; Wettstein and Mearns 2002; Cellitti et al. 2006; Guirguis et al. 2011; Sillmann et al. 2011). There are substantial modulations of temperature extremes by ocean-oriented climate modes such as the Madden-Julian oscillation (MJO) (Jeong et al. 2005) and El Niño-Southern Oscillation (ENSO) for the longer time scale (Higgins et al. 2002; Meehl et al. 2007; Alexander et al. 2009; Lim and Schubert 2011). Recent studies clearly demonstrate the geographical dependency of the modulation of temperature extremes by larger-scale teleconnection patterns such as NAO, PNA, ENSO, and the Pacific decadal oscillation (PDO) (Loikith and Broccoli 2014; Westby et al. 2013). However, those teleconnection patterns are distinct from the large-scale meteorological patterns (LSMPs) associated with temperature extremes (e.g., hot spells) both in spatial pattern and in time scale. As shown in Grotjahn (2011), when the LSMP is present with positive sign and sufficient strength (normalized circulation index $>1.6$ ), then CCV extreme surface temperatures usually occur on that day, and hence sufficient amplitude of the LSMP is as rare as the temperature extremes. The LSMPs associated with specific temperature extremes are described in much fewer studies (Grotjahn and Faure 2008; Gershunov et al. 2009; Loikith and Broccoli 2012; Bumbaco et al. 2013) than are studies of teleconnection patterns. A review of statistical methods, synoptic dynamics, modeling, and trends relating to temperature extremes in the LSMP context is presented by Grotjahn et al. (2015). The LSMPs for extreme heat events are not fully understood for different parts of North America, including the $\mathrm{CCV}$, providing a motivation for this study.

Regional-scale heat events may be influenced by land conditions at the surface or below. Land-use and landcover change (e.g., from irrigated farm to urban area) can amplify the area experiencing extreme heat (Grossman-Clarke et al. 2010; Wang et al. 2013). Soil moisture deficit strongly contributes to hot extremes in some regions, such as the central United States, Australia, and much of Europe (Fischer et al. 2007; Hirschi et al. 2011; Yin et al. 2014). However, soil moisture deficit is not a major factor for the CCV because most farmlands in the CCV are heavily irrigated. The CCV is geographically complex (Fig. 1), where local thermally driven circulations caused by terrain slope (mountainvalley winds) are mixed with land-sea breezes. Because hot spells are associated with easterly flows (Grotjahn 2011), air moving in that direction sinks down into the CCV, warms adiabatically, and opposes a cooling sea breeze while also lowering the subsidence inversion and thereby reducing the volume of air heated by surface heat fluxes generated by sunshine. These conditions all favor the formation of extreme hot spells.

Prior studies found that summertime hot spells in the $\mathrm{CCV}$ area are closely linked to LSMPs that are an equivalent barotropic, nearly stationary wave train (ridge-trough-ridge pattern) across the North Pacific and western North America (Grotjahn and Faure 2008; Grotjahn 2011, 2013). Grotjahn and Faure (2008) describe the formation of the hot-spell LSMP with apparent westward wave motion (in the southern part) and eastward development from a western Pacific ridge to a mid-Pacific trough, and then to a North American west coast ridge (in the northern part) using composite maps prior to onset of 18 extreme events over 22 summer seasons. Grotjahn (2011) defined a metric to identify how well a given day's weather pattern matches the hotspell composite LSMP from 1979 to 2010. This study extends the period of study of CCV hot-spell LSMPs and examines them more closely.

A primary question considered in the current study is, what is the source of the hot air present in the heat wave? This question led the authors to calculate backward-in-time trajectories. It was immediately apparent that the trajectories of $\mathrm{CCV}$ hot spells are roughly divided into two groups. The next question is, do those two paths represent two distinct ways to generate CCV hot-spell conditions? Using objective tools, this paper classifies CCV hot spells into two types based on the temporal and spatial evolution of LSMPs, provides direct statistical and structural comparisons between the two types, and uncovers some key dynamical differences that lead to the distinct types.

The paper organization is as follows. Section 2 outlines the dataset and methods used. Section 3 presents the classification of two different types of CCV heat waves and corresponding LSMPs. Section 4 provides the dynamical differences that drive two distinct hot spells. Last, section 5 summarizes the results.

\section{Data and methods}

\section{a. Synoptic and reanalysis dataset}

This study uses daily maximum near-surface temperature at 15 stations provided by the National Climatic Data Center (NCDC; http://www.ncdc.noaa.gov/dataaccess/land-based-station-data) (in Fig. 1). Among 23 stations, 5 stations are excluded because of their location 


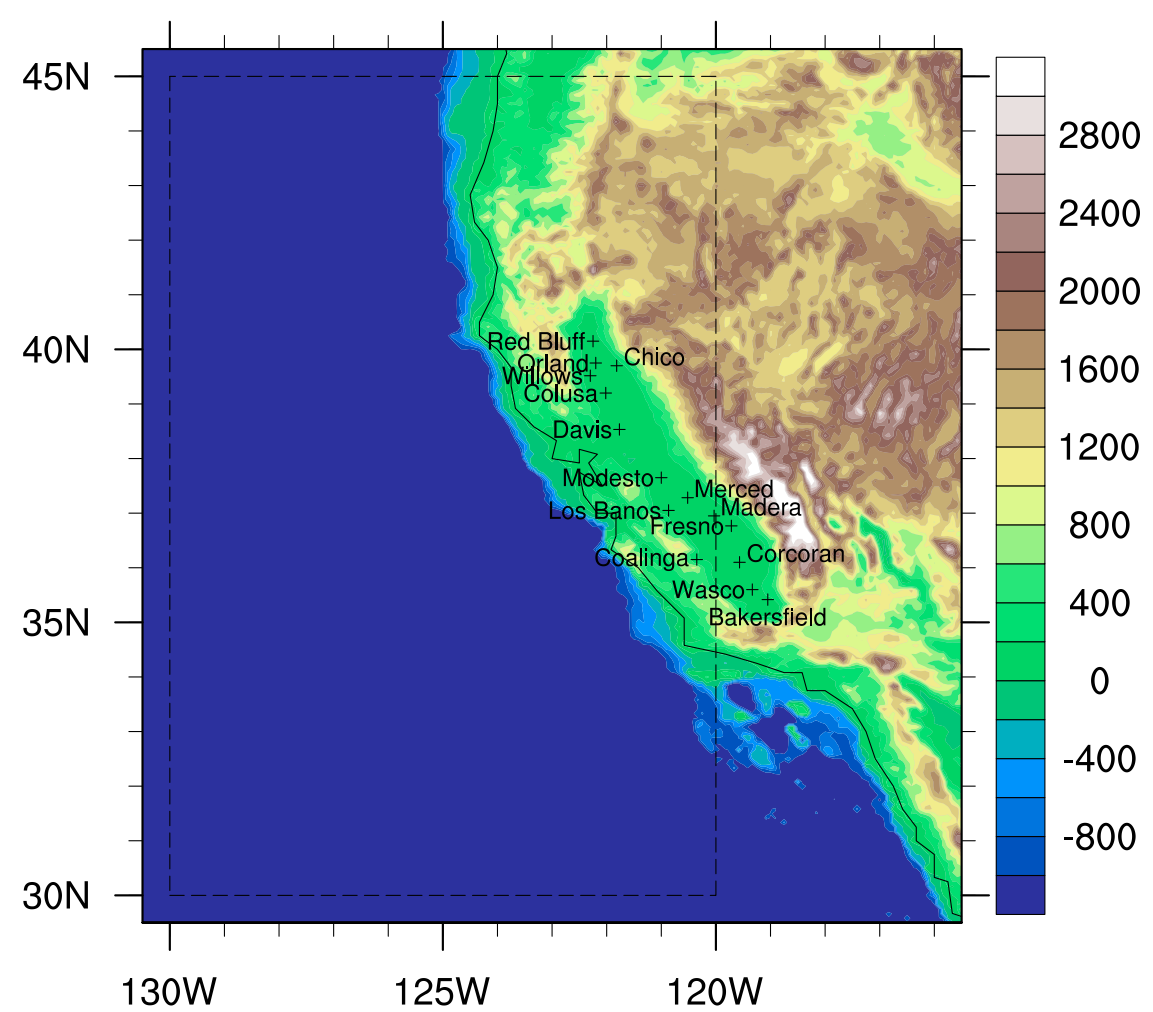

FIG. 1. Geographic location of 15 CCV NCDC stations (marked by plus symbols) used in our heat wave criteria. The dashed box region represents the TA area.

in the delta, a region where weak sea breezes can provide local, short interruptions of heat waves that are not experienced elsewhere in the CCV. Three more stations are excluded for being close to other NCDC stations, thereby creating a relatively even distribution of stations over the CCV (the eight stations excluded are omitted in Fig. 1).

This study analyzes upper-air LSMPs derived from the National Centers for Environmental PredictionNational Center for Atmospheric Research reanalysis dataset (R-1) (Kalnay et al. 1996). Time and spatial resolution of R-1 is 6 hourly and $2.5^{\circ}$ longitude $\times 2.5^{\circ}$ latitude. We consider boreal summer season extending from June through September (JJAS; 122 days) and the time period from 1977 to 2010 (34 years). The choice of data and time period was a compromise between having more events (larger sample) while also maintaining relatively high accuracy of the reanalysis data as a result of the assimilation of satellite observations.

\section{b. Event isolation}

Space and time criteria are used to identify CCV hotspell events from the NCDC station data. By considering duration and spatial coverage together, this method isolates those events in which a majority of CCV stations experience hot weather commonly for sufficient time.
The method is as follows: 1) calculate 15 stations' daily maximum temperature anomalies (relative to each station's long-term daily mean), 2) normalize these anomalies by long-term daily mean standard deviation for each station, 3 ) select the $5 \%$ hottest dates for each station, 4) retain those dates common to at least six stations, and 5) isolate events when there are at least three consecutive retained dates in a row within JJAS and the interval between two events is six days or longer. The 6-day interval was chosen based upon the autocorrelation function being $<0.05$ for all CCV stations collectively and nearly all individually for lead or lag times greater than six days (see Fig. S2 in the supplementary material). This process identified 28 heat wave events for the CCV (Table 1). Dividing the 1977-2010 data into four periods - three 9-yr periods followed by a 7-yr period - we find an approximately even distribution of hot-spell occurrences (seven, eight, six, and seven, respectively). This space and time method detects heat waves based on extreme temperatures across the $\mathrm{CCV}$, but it results in a small sample size of about one event per year. The intention behind choosing such rare events is that the dynamics responsible for these extremes will have a stronger signal among the "noise" of natural variability.

Consistent with Grotjahn (2011), we assign 1200 UTC as the onset for every event. Although 0000 UTC (the 
TABLE 1. Start and end dates and duration of $28 \mathrm{CCV}$ hot spells considered. Events in boldface are mixed type and could not be assigned strongly to either cluster.

\begin{tabular}{|c|c|c|c|c|}
\hline Event No. & Cluster & Event start date & Event end date & Duration (days) \\
\hline 1 & 1 & 5 Jun 1977 & 7 Jun 1977 & 3 \\
\hline 2 & 1 & 6 Sep 1977 & 8 Sep 1977 & 3 \\
\hline 3 & 2 & 5 Jun 1978 & 7 Jun 1978 & 3 \\
\hline 4 & - & 5 Aug 1978 & 9 Aug 1978 & 5 \\
\hline 5 & 1 & 12 Sep 1979 & 17 Sep 1979 & 6 \\
\hline 6 & - & 24 Jul 1980 & 27 Jul 1980 & 4 \\
\hline 7 & 1 & 11 Jun 1985 & 17 Jun 1985 & 7 \\
\hline 8 & 1 & 17 Jul 1988 & 19 Jul 1988 & 3 \\
\hline 9 & 2 & 25 Aug 1988 & 27 Aug 1988 & 3 \\
\hline 10 & 2 & 3 Sep 1988 & 6 Sep 1988 & 4 \\
\hline 11 & 2 & 12 Jul 1990 & 14 Jul 1990 & 3 \\
\hline 12 & - & 5 Aug 1990 & 10 Aug 1990 & 6 \\
\hline 13 & 1 & 2 Jul 1991 & 5 Jul 1991 & 4 \\
\hline 14 & 2 & 2 Jun 1992 & 4 Jun 1992 & 3 \\
\hline 15 & 2 & 16 Aug 1992 & 20 Aug 1992 & 5 \\
\hline 16 & 1 & 2 Jun 1996 & 7 Jun 1996 & 6 \\
\hline 17 & 2 & 10 Aug 1996 & 15 Aug 1996 & 6 \\
\hline 18 & 1 & 3 Aug 1998 & 5 Aug 1998 & 3 \\
\hline 19 & 2 & 30 Aug 1998 & 3 Sep 1998 & 5 \\
\hline 20 & 2 & 18 Sep 2000 & 20 Sep 2000 & 3 \\
\hline 21 & 1 & $10 \mathrm{Jul} 2002$ & $12 \mathrm{Jul} 2002$ & 3 \\
\hline 22 & 1 & 22 Jun 2006 & 24 Jun 2006 & 3 \\
\hline 23 & 1 & $20 \mathrm{Jul} 2006$ & $26 \mathrm{Jul} 2006$ & 7 \\
\hline 24 & 1 & 7 Jul 2008 & $10 \mathrm{Jul} 2008$ & 4 \\
\hline 25 & 1 & 27 Aug 2008 & 29 Aug 2008 & 3 \\
\hline 26 & - & 5 Sep 2008 & 7 Sep 2008 & 3 \\
\hline 27 & 2 & 25 Sep 2009 & 27 Sep 2009 & 3 \\
\hline 28 & - & 27 Sep 2010 & 29 Sep 2010 & 3 \\
\hline \multirow[t]{2}{*}{ Cluster avg } & 1 & - & - & 4.2 \\
\hline & 2 & - & - & 3.8 \\
\hline \multirow[t]{2}{*}{ Cluster std dev } & 1 & - & - & 1.6 \\
\hline & 2 & - & - & 1.1 \\
\hline
\end{tabular}

next day) is closer to the local time (2300 UTC) of highest surface temperature, upper-air charts at the earlier time (1200 UTC) have more predictability (Grotjahn 2011).

\section{c. Identification of distinct LSMPs prior to heat wave onset}

\section{1) BACKWARD TRAJECTORIES}

Prior work (Grotjahn and Faure 2008; Grotjahn 2011, 2013) found the maximum upper-air temperature anomaly (at $850 \mathrm{hPa}$ ) to be centered just off the west coast of North America, near the California-Oregon border. Backward trajectories from this area of highest temperature (plus analysis of individual terms in the temperature equation, not shown) were calculated to answer the question of how high temperatures develop there. The backward trajectory calculation uses 6-hourly reanalysis data. The procedure starts with identifying threedimensional wind $\left(u_{1}, v_{1}, \omega_{1}\right)$ and elevation estimation $z_{1}$, hypothesizing hydrostatic balance in a homogeneous atmosphere at six grid points [the combinations of two longitudes $\left(122.5^{\circ}\right.$ and $\left.125^{\circ} \mathrm{W}\right)$ and three latitudes $\left(35^{\circ}\right.$, $37.5^{\circ}$, and $\left.40^{\circ} \mathrm{N}\right)$ ] at $850 \mathrm{hPa}$ at the onset time. The threedimensional wind field is used to estimate the distance traveled over the prior six hours. The scheme includes the convergence of meridians when calculating zonal distance traveled. The scheme finds a first guess of each parcel location $\left(\theta_{2}, \varphi_{2}, p_{2}\right)$ six hours before by subtracting the longitudinal, latitudinal, and pressure distances from the original location $\left(\theta_{1}, \varphi_{1}, p_{1}\right)$. Next, the three-dimensional wind $\left(u_{2}, v_{2}, \omega_{2}\right)$ is estimated at the first guess location by applying bilinear interpolation. The final location $\left(\theta_{0}, \varphi_{0}, p_{0}\right)$ of each air parcel six hours before the original time is estimated by calculating again the longitudinal, latitudinal, and pressure distances from the averaged three-dimensional wind $\left[\left(u_{1}+u_{2}\right) / 2,\left(v_{1}+\right.\right.$ $\left.\left.v_{2}\right) / 2,\left(\omega_{1}+\omega_{2}\right) / 2\right]$. These procedures are repeated for prior times in 6-h steps totaling several days. The locations are plotted as projections onto two-dimensional planes in a trajectory diagram. The trajectory diagram (shown later) plots one average patch calculated from 
these six paths for each event. The individual and the average trajectories appeared to identify two different types of paths that lead up to a similar LSMP at the event onset. Grouping the cases based on these two types of paths, and after close inspection of the fields of individual events, we chose portions of three anomalous fields as "target fields" for the hot-spell classification: 700-hPa zonal wind at two days lead, 600-hPa temperature at two days lead, and 700-hPa temperature at one day lead over the domain of $20^{\circ}-60^{\circ} \mathrm{N}, 150^{\circ}-100^{\circ} \mathrm{W}$.

\section{2) Clustering techniques}

Clustering analysis is able to group similar patterns prior to onset among 28 events, therefore providing a quantitative tool to isolate distinct origins of the heat waves. In this study, the $k$-means clustering technique is applied to the target fields defined above. Simply, this is an iterative algorithm moving events from one group to another until there is no additional improvement in minimizing the overall distance between patterns among events in resultant groups. For instance, the distance can be defined as the squared Euclidean point-to-centroid distance in a group, where each centroid is the mean of the patterns in its cluster (Spath 1985; Seber 2009). This method has been widely used in the atmospheric research not only associated with the relationship between LSMPs and extreme weather (Park et al. 2011; Stefanon et al. 2012) but also for assessing the climate model performance (Lee and Black 2013; Westby et al. 2013). It should be noted that cluster results can be strongly dependent on the selection of the target fields to be used by the cluster analysis. (However, in a companion study submitted elsewhere, using other levels retrieved the same cluster memberships.) In every iteration step, the clustering procedure creates clusters objectively, but the process is not entirely objective, as the target fields are chosen a priori and those choices make the calculation partly self-referential.

Two concerns arise when applying $k$-means clustering to atmospheric extremes: 1) there is uncertainty in choosing an optimal number of clusters $k$, and 2) assigning an event to one cluster rather than another is less clear when the sample size is small. To address these concerns we used the distinctly different backward trajectories to make an initial partitioning of cases. Next we examined the composites, and very different evolutions of the LSMPs were clearly apparent. Then we decided to apply spatiotemporal cluster detection to a small number of variable and level combinations at times shortly before heat wave onset. We applied an analogy of the "distance of dissimilarity" metric [as in Stefanon et al. (2012)] to judge the optimal number $k$. The number $k$ with an abrupt drop of intercluster distance for the next higher value $k+1$ is considered the optimal number of clusters. Intercluster distance of our target fields has a notably abrupt drop from $k=2$ to higher $k$ (not shown). A larger number for $k$ may represent less ambiguity in the classification. However, clustering analysis aims mainly to gain a physical insight for heat wave formation, which is possible with a minimal number of distinct groups and not a separate group for every single event. The distance of dissimilarity metric as well as our qualitative analyses of trajectories led us to choose $k=2$ clusters in this study. In addition, spatial projection analysis is applied to assess how well individual events sort into the two clusters. Projection coefficients $p_{k, j}$ of the $j$ th event against the $k$ th cluster composite means are calculated for the same domain of the target fields above:

$$
p_{k, j}=\frac{\sum_{i=1}^{N}\left(x_{i}^{j} y_{i}^{k}\right)}{\sum_{i=1}^{N}\left(y_{i}^{k}\right)^{2}}, \text { for } k=1,2 \text { and } j=1, \ldots, n
$$

where $k$ is a cluster, $j$ is an event, $i$ is a grid point, $n$ is the total number of events, $N$ is the total number of grid points, $x$ is the field of a variable of individual events $j$ to be projected, and $y$ is the composite mean field of $x$ for two clusters. The projections are plotted as a scatterplot in Fig. 2. In the scatterplot, one sees that individual events do seem to fall into groups where the projection on one cluster mean is much higher than the projection onto the other cluster mean. However, some events have LSMP structure that does not strongly favor one cluster mean over the other. These "mixed" events were identified as follows. Initially, the maps for all events were processed with a clustering algorithm detailed above using $k=2$. Then cluster averages were formed from the members of these two clusters. Using those cluster means, each event was projected onto both cluster means. The membership of each cluster was revised by requiring that the new projection of an event onto that cluster be more than twice the projection of that event onto the other cluster mean. Events that did not satisfy the twice-projection criterion were identified as mixed events, which tend to be a mixture of both types of clusters. Such mixed events were then excluded from the final cluster definitions, thereby isolating more strongly the two types of clusters. Of the 28 events during this time period, 5 mixed events were excluded. After excluding the mixed events, new cluster composites were calculated from the two revised clusters of events, and projection coefficients were calculated again with respect to these new cluster composites and plotted. 


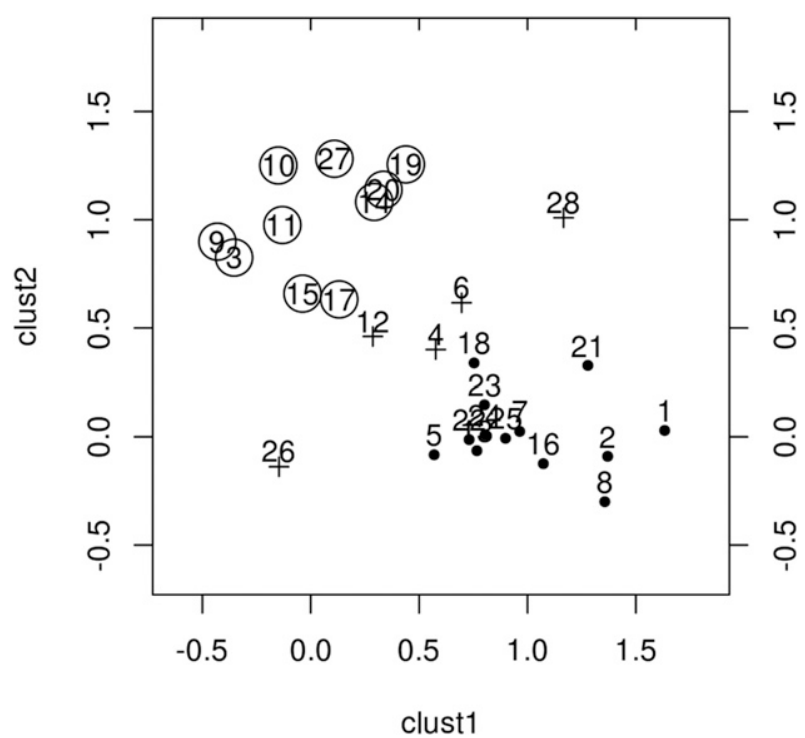

FIG. 2. Scatterplot of two projection coefficients for each of the 28 events. The numbers match the event numbers specified in Table 1. A dot marks each event in cluster 1, a circled number for each event in cluster 2, and mixed events are marked with a plus symbol. For individual events, three anomalous fields (-2-day zonal wind at $700 \mathrm{hPa},-2$-day temperature at $600 \mathrm{hPa}$, and -1-day temperature at $700 \mathrm{hPa}$ ) are projected onto their composites of two clusters over $20^{\circ}-60^{\circ} \mathrm{N}, 150^{\circ}-100^{\circ} \mathrm{W}$, then the average of three coefficients are plotted. Five undetermined and/or mixed events are excluded from the analysis hereafter.

\section{3) WAVE ACTIVITY FLUX}

This study analyzes the wave activity flux (WAF), as defined by Takaya and Nakamura (2001), to track the propagation of wave energy. Unlike the Eliassen-Palm flux (Edmon et al. 1980) and the wave activity flux developed by Plumb (1986), this method allows one to make a snapshot analysis since it does not include any time averaging. Therefore, the time evolution is tracked of the wave activity associated with development of each heat wave. Under a conservation law, the wave activity is related with the wave enstrophy and wave kinetic and internal energy, and part of those two factors is closely connected to the temperature. Since this method assumes a linear geostrophic streamfunction $(\psi=\Phi / f)$, the wave activity is also related to the geopotential $(\Phi)$ perturbation. Takaya and Nakamura (2001) show that this WAF is locally parallel to the group velocity of quasigeostrophic Rossby wave packets. The WAF vectors show movement of collocated geopotential ridges and troughs. One might approximately interpret daily weather charts as follows: Convergence of WAF at a ridge in geopotential height is expected to amplify the ridge to the extent that the ridge is a deviation from a horizontal mean field. (Local change of wave activity is proportional to convergence of WAF if one neglects diabatic effects.) The same geopotential ridge would decay if WAF was diverging there. Depending upon where the WAF convergence and divergence occur relative to the geopotential pattern, the WAF convergence and divergence zones can be interpreted as driving propagation as well as amplitude changes of the troughs and ridges. The Takaya and Nakamura (2001) WAF formulation has been applied to understand the dynamics of many phenomena. For example, the converging of wave activity flux into the amplifying blocking ridge and attendant wave activity flux divergence upstream of the blocking ridge is known to influence the blocking formation over Siberia (Nakamura et al. 1997; Takaya and Nakamura 2001). Here, the WAF is used to interpret the temperature increase and corresponding ridge formation along the North American west coast that are associated with hot spells.

\section{4) LEAD-LAG COMPOSITE}

Another tool used to understand the time evolution is to form composites of total and daily anomaly fields of atmospheric variables and WAF for individual clusters at fixed times prior to the event onset time. These clearly show differences between the clusters in temporal and spatial development of corresponding LSMPs and related dynamics. Although the sample size is small for each cluster, the patterns and their evolution are consistent among the events within a cluster. The consistency is measured by counting the number of events with the same sign of the anomaly at each grid point, a procedure called sign counts (Grotjahn 2011). Sign counts are calculated as follows: in a cluster, the number of events with negative sign at a grid point is subtracted from the number of events having positive sign at that grid point; that difference is then divided by the total number of events in that cluster to facilitate comparison among clusters having differing numbers of events. Hence, a sign count of 1.0 means all events in that cluster have positive anomaly at that grid point. A sign count of $-1 / 3$ means $2 / 3$ of the events have negative anomaly at that grid point.

\section{Two different types of $\mathrm{CCV}$ heat waves}

\section{a. Classification of CCV heat wave events}

The heat wave selection criteria identify 28 events in the period 1977-2010. These events can be grouped into two types by $k$-means clustering techniques discussed in section 2. The first cluster has 13 members while the second cluster has 10 events. Both clusters are spread relatively evenly over the 34 summer seasons studied, although the first cluster (identified in the second column of Table 1) is more common in the decade of 2001-10. 
600hPa, Day -2.5

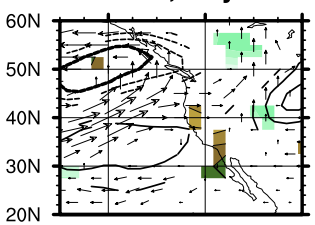

$700 \mathrm{hPa}$, Day -2.5
600hPa, Day -2

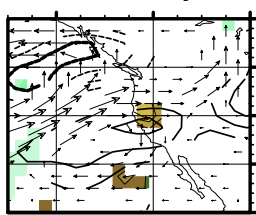

$700 \mathrm{hPa}$, Day -2

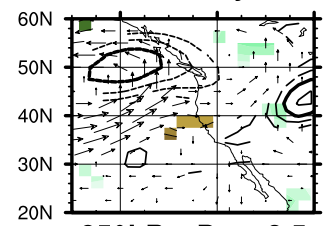

850hPa, Day -2.5
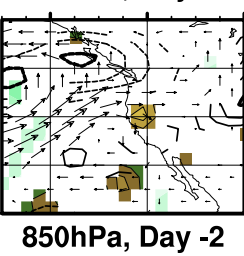

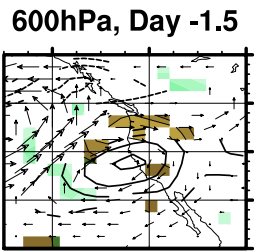

$700 \mathrm{hPa}$, Day -1.5

600hPa, Day -1

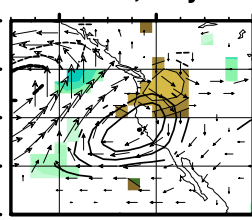

$700 \mathrm{hPa}$, Day -1

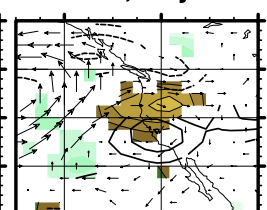

850hPa, Day -1.5

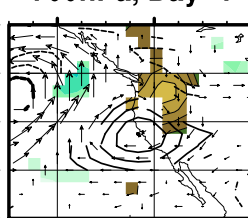

850hPa, Day -1
600hPa, Day -0.5

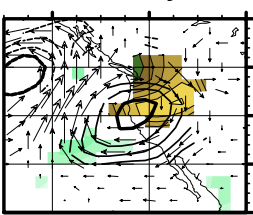

$700 \mathrm{hPa}$, Day -0.5

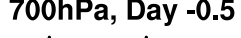

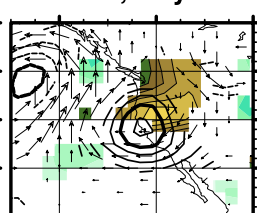

$850 \mathrm{hPa}$, Day -0.5

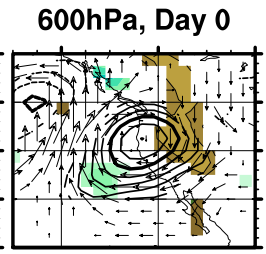

700hPa, Day 0

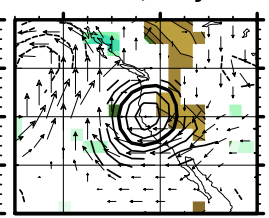

850hPa, Day 0
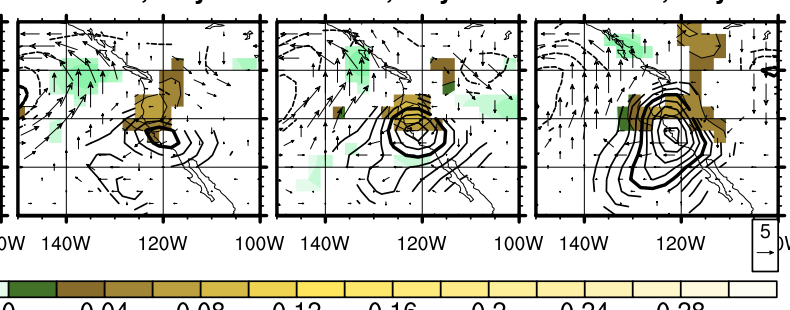

$-0.28$ $-0.24$ $-0.2$

$-0.16 \quad-0.12$
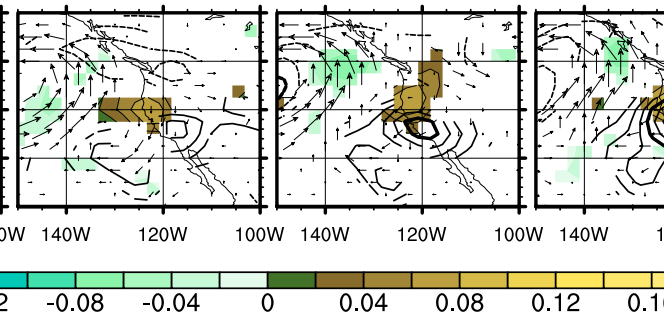

FIG. 3. Anomalous composite of air temperature (K; contours), horizontal wind ( $\mathrm{m} \mathrm{s}^{-1}$; vectors), and omega (pressure vertical velocity, $\mathrm{Pa} \mathrm{s}^{-1}$; shading) for cluster 1 . For all three fields, only grid points that have sign counts with magnitude over $1 / 3$ of cluster member numbers are plotted. Vectors are plotted at the grids where either the zonal or meridional component passes the $1 / 3$ sign counts criteria. Contour interval is $0.7 \mathrm{~K}$ ( $3.5 \mathrm{~K}$ for thick contours) and dashed contours are negative values. For clarity, only positive omega shadings are shown with temperature contours.

Regarding the duration of events, the second cluster shows shorter persistence (3.8 days) on average than does the first cluster (4.2 days), although this duration difference is not significant at the $95 \%$ confidence level. To ensure the fidelity of the two groups, apart from the "dissimilarity index," spatial projection coefficients of individual LSMPs are calculated for each of the two revised cluster composites and their distribution plotted as a scatter diagram in Fig. 2. Since the spatial projection coefficient indicates similarity of the shape and magnitude, the fidelity of dividing events into groups is apparent because 1) individual events have a coefficient that is at least more than twice as large in one cluster composite than in the other, 2) events tend to collect in groups, and 3) the groups are distinctly separate on the scatterplot. The two types of heat wave grouping satisfy these three conditions very well. However, of the 28 events, 5 events are mixtures of the two types and are excluded from the analyses after this point.

\section{b. Temporal and spatial evolution of anomalous LSMPs: Temperature, horizontal wind, and omega}

This study focuses on LSMPs during the two different ways CCV heat waves develop; therefore, the focus is upon anomalous fields of air temperature, horizontal wind, and omega (equivalently the pressure velocity, or vertical motion in isobaric coordinates) at three pressure levels $(850,700$, and $600 \mathrm{hPa})$ for several days prior to the event onset. These time and space domains are consistent with those used by the clustering analysis. At onset time, both clusters (contours in right-hand column in both Fig. 3 and Fig. 4) commonly have a peak of temperature anomalies (TA) centered near but off the Northern California coast and extending outward, including over the CCV area (this region is referred to as the TA area). The domain enclosed by the dashed lines in Fig. 1 is the TA area. Grotjahn (2011) emphasizes the consequences of a warm temperature anomaly in the TA area, as it creates a thermal low at the coast and the lowlevel pressure gradient opposes a sea breeze from cooling the CCV. While there is similarity in the TA area at onset, elsewhere the differences between clusters in the spatial coverage and magnitude of the temperature anomalies are remarkable. In the first cluster strong warm anomalies cover mostly California with a lobe into the eastern Pacific (Fig. 3). In the second cluster the strong warm anomaly has a lobe over the northwestern United States, including a second peak over Washington (Fig. 4). In magnitude, this ensemble mean temperature anomaly at $850 \mathrm{hPa}$ is hotter in the second cluster than in the first cluster. At higher levels the temperature anomaly is a bit weaker over the TA area in the second 
600hPa, Day -2.5 600hPa, Day $-2 \quad 600 \mathrm{hPa}$, Day -1.5
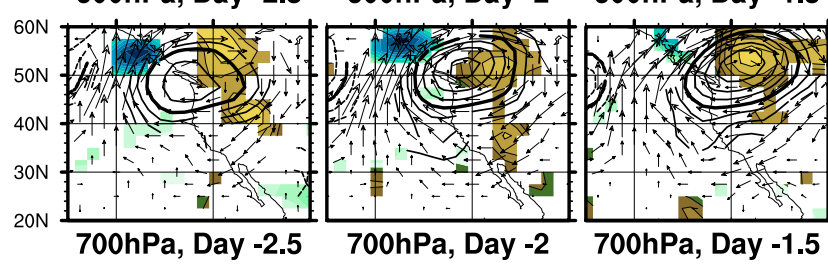

$600 \mathrm{hPa}$, Day -1

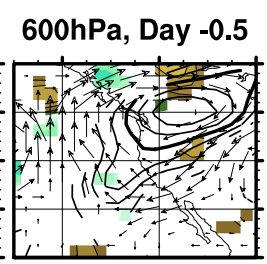

$700 \mathrm{hPa}$, Day -1.5
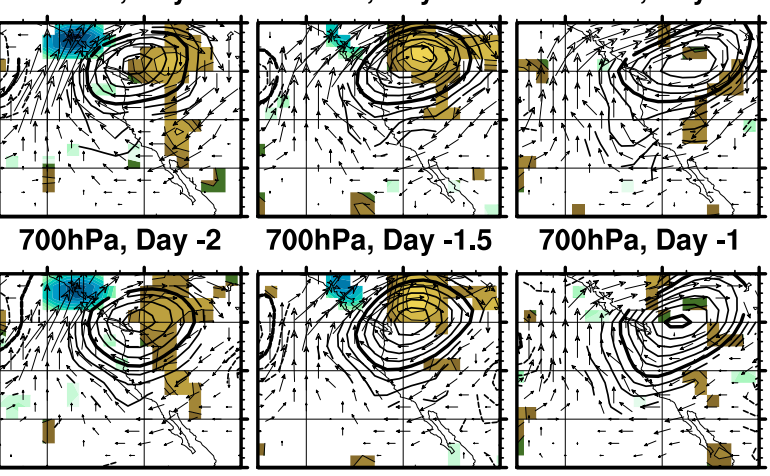

$700 \mathrm{hPa}$, Day -1

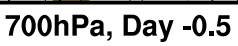

600hPa, Day 0

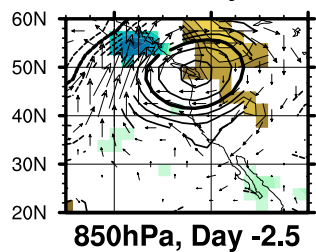

850hPa, Day -2
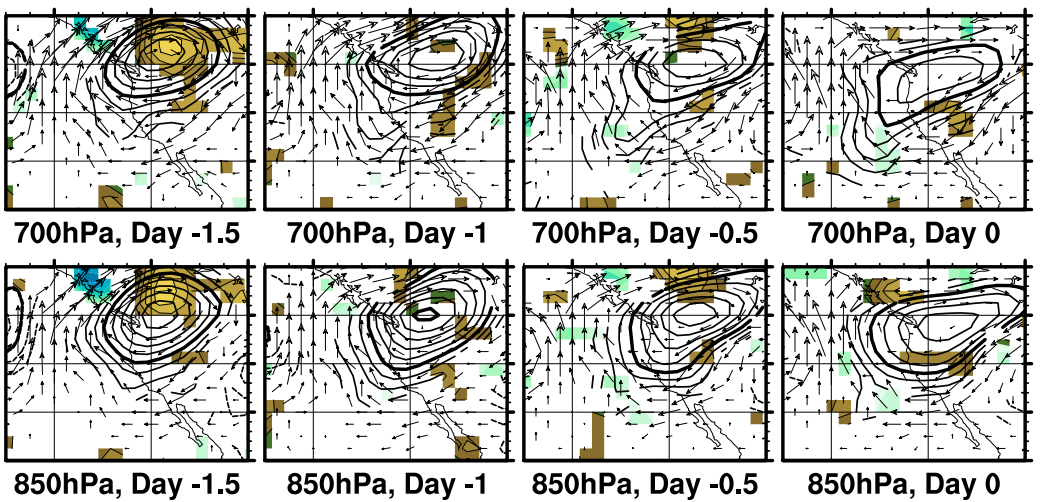

$700 \mathrm{hPa}$, Day 0

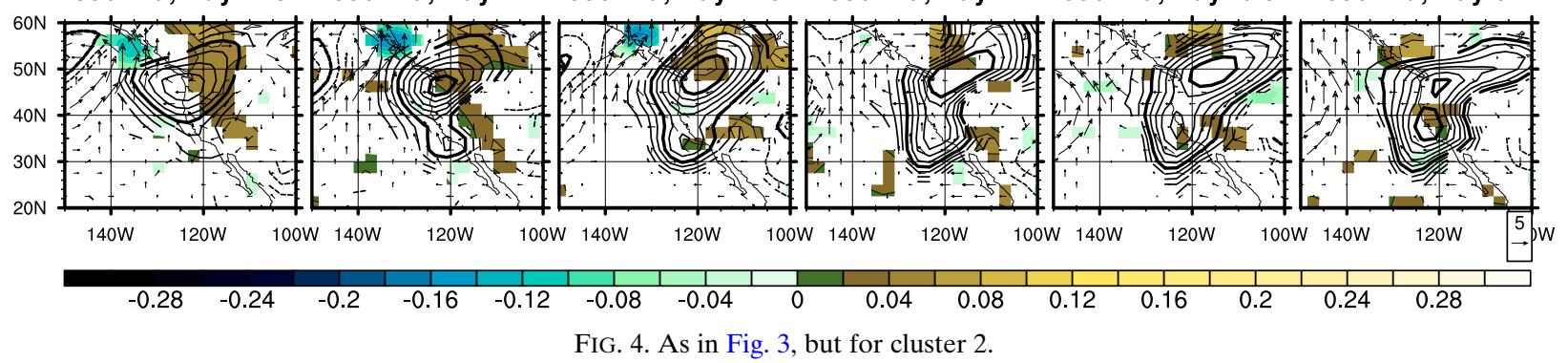

cluster, although the peak values are higher in cluster 2 and an anomaly is centered some distance to the northeast of the area.

Leading up to the event onset, one main difference between the clusters is that cluster 2 has a hot spell over the northwestern United States before the CCV hotspell onset. The second cluster has very strong equivalent barotropic warm anomaly through the depth of the troposphere for several days prior to the onset. The first cluster does not have this preexisting hot anomaly but develops it first over the TA area. In the second cluster, a part of that northwestern U.S. hot spell's southern tail expands over the CCV area; as the northwestern hot spell weakens the TA area temperature anomaly amplifies, especially in the lower troposphere.

Anomaly omega composites show a significant zonal dipole of rising-sinking motion in both clusters (shading in Figs. 3 and 4). The second cluster has a stronger dipole, which is centered at a higher latitude at a 2-day lead, than the dipole in the first cluster, which peaks at 1-day lead. Sinking motion located over the landmass is very important to the formation of the temperature maximum in the TA area because of adiabatic compressional heating. The first cluster shows local subsidence of air at the north boundary of the TA area that increases over time until just before onset. The second cluster has very strong sinking motion covering much of inland western North America during a 2.5-1.5-day lead; at onset the sinking wanes to the north and waxes over the north and east half of the TA area. As detailed in Grotjahn (2011), this local sinking motion is crucial for the intensification of the CCV hot spells because of adiabatic compression and by lowering the climatological summertime subsidence inversion.

Formation of the heat wave in both clusters is linked to horizontal advection of the anomalously hot air. The anomalous horizontal flow upstream of the TA area is generally coming from a region of anomalous sinking motion (Figs. 3 and 4). However, the direction of that motion is distinctly different between the two clusters (vectors in Figs. 3-6). Total fields (Figs. 5 and 6) clearly show the diurnal cycle in both clusters. The time 0000 UTC (2.5-, 1.5-, and 0.5-day lead) is close to the local time of highest surface temperature. Along with the diurnal cycle, one might expect a sea-land breeze. At the onset and 850-hPa level, the total fields show offshore or alongshore flow in the total fields (Figs. 5 and 6) with anomalous easterlies in the TA area (Figs. 3 and 4).

For the first cluster, at later stages (from 1.5-day lead to onset), winds approach the TA area from a southwesterly direction. The wind direction then turns northwesterly or northerly while passing through an area of strong subsidence on the northwest side of the TA area (Fig. 5), incorporating the enhanced subsidence to the north (Fig. 3). In Fig. 3 the sinking anomaly is strongest in the afternoon (1.5- and 0.5-day lead), counteracting diurnal rising that otherwise might occur. Prior to that time (2.5- and 2.0-day lead), there is 
600hPa, Day -2.5 600hPa, Day -2
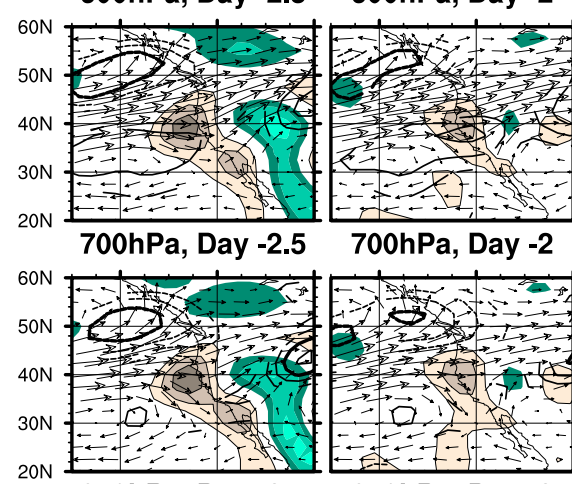

850hPa, Day -2.5

$700 \mathrm{hPa}$, Day -2
600hPa, Day -1.5

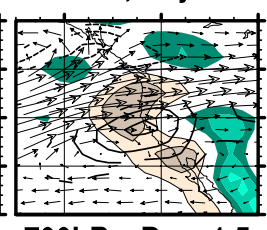

700hPa, Day -1.5
600hPa, Day -1

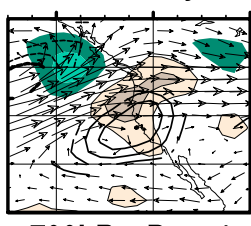

700hPa, Day -1

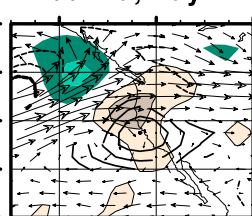

$850 \mathrm{hPa}$, Day -1

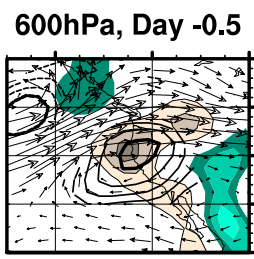

700hPa, Day -0.5

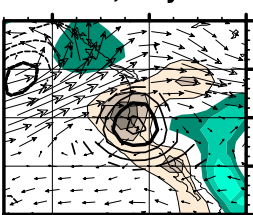

850hPa, Day -0.5
600hPa, Day 0

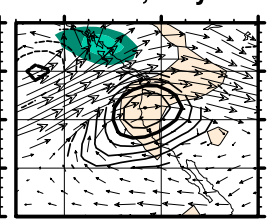

700hPa, Day 0

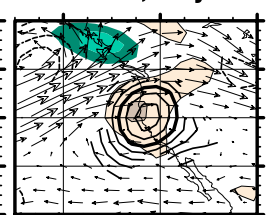

$850 \mathrm{hPa}$, Day 0

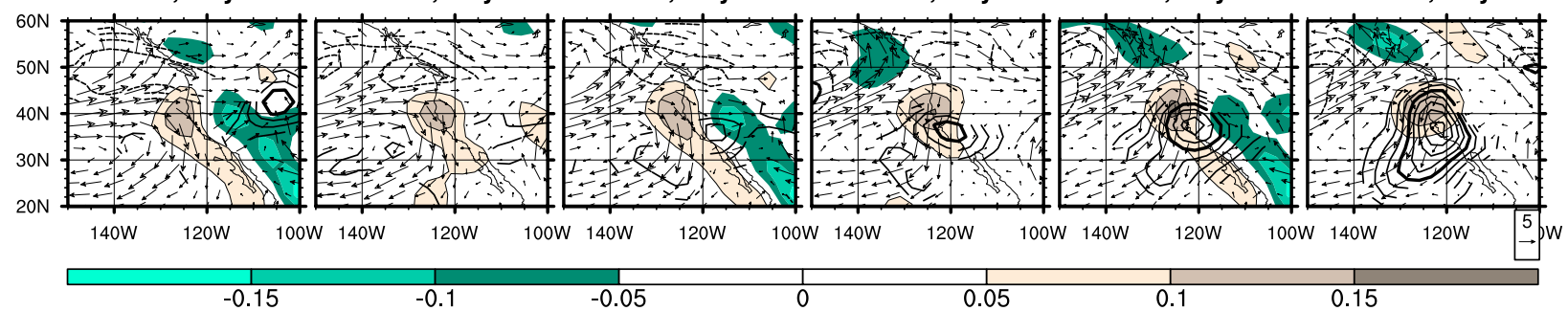

FIG. 5. Composite of air temperature anomalies (K; contours), total horizontal wind ( $\mathrm{m} \mathrm{s}^{-1}$; vectors), and total omega (Pa s ${ }^{-1}$; shading) for cluster 1 . For the air temperature anomalies, only grid points that have sign counts with magnitude over $1 / 3$ of cluster member numbers are plotted. Contour interval is $0.7 \mathrm{~K}$ ( $3.5 \mathrm{~K}$ for thick contours) and dashed contours are negative values. For clarity, only positive omega shadings are shown with temperature contours.

anomalously strong southwesterly flow offshore (Fig. 3) that amplifies a strongly westerly total wind (Fig. 5). Backward trajectories (Fig. 7) will link these motions leading to paths that are crossing the eastern North Pacific before turning southward and sinking near the TA area.

In the second cluster the anomalous flow several days prior to onset (2.5-1.5-day lead) is strongly southerly, becoming southeasterly at the west coast (Fig. 4) such that the total flow near the coast (Fig. 6) is much weaker (and in many places has opposite direction) at the TA area than in the other cluster. As with the other cluster, the motion that reaches the TA area passes through sinking off the west coast (Fig. 6), although prior to onset most of the sinking is centered on the south side of the TA area. Anomalous sinking (Fig. 4) opposes rising (Fig. 6) over the Rockies for several days prior to onset; only at onset does the anomalous sinking (Fig. 4) enhance subsidence at the TA area (Fig. 6). The weak total winds means that air parcels in the TA area do not travel far. The anomalous winds are southeasterly in southern Nevada and southern deserts of California and also have an easterly component in northern Nevada and California (Fig. 4). The centering of the sinking on the southwest side of the TA region (with southerly and southeasterly winds) followed by sinking on the north side (with northerly winds) at onset suggests cluster mean parcels will come from the south and east in cluster 2. Backward trajectories (Fig. 7) show the anticipated properties: these trajectories generally do not sink as much as those in the other cluster, their horizontal distances traveled are less, and the direction traveled has more variation between events in this cluster. However, several of the trajectory paths of cluster 2 arrive at the TA area from the desert region to the southeast. Cluster 2 has strong westerlies, similar to cluster 1 , but they are located much farther north because of the preexisting temperature anomaly (and geopotential ridge) centered near northwestern North America.

Air parcels that arrive at $850 \mathrm{hPa}$ in the TA area are tracked over four days prior to onset by the backward trajectory scheme described in section 2 . The average path for each event is plotted in Fig. 7. The paths are consistent with motions anticipated in the discussion of the LSMP wind components above. Most air parcels in cluster 1 move from the west while sinking as they approach the TA area before heat wave onset. Two paths have brief periods of rising motion before sinking (events 7 and 22). Other paths approach the TA area from the south, east, or northeast (events 3, 9-11, 15, 17, and 27); these paths are all in cluster 2. Different starting 
600hPa, Day -2.5 600hPa, Day -2 600hPa, Day -1.5
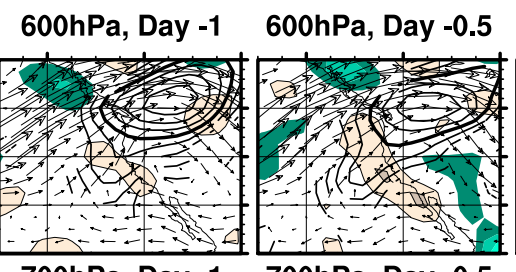

$700 \mathrm{hPa}$, Day $-1700 \mathrm{hPa}$, Day -0.5

$600 \mathrm{hPa}$, Day 0
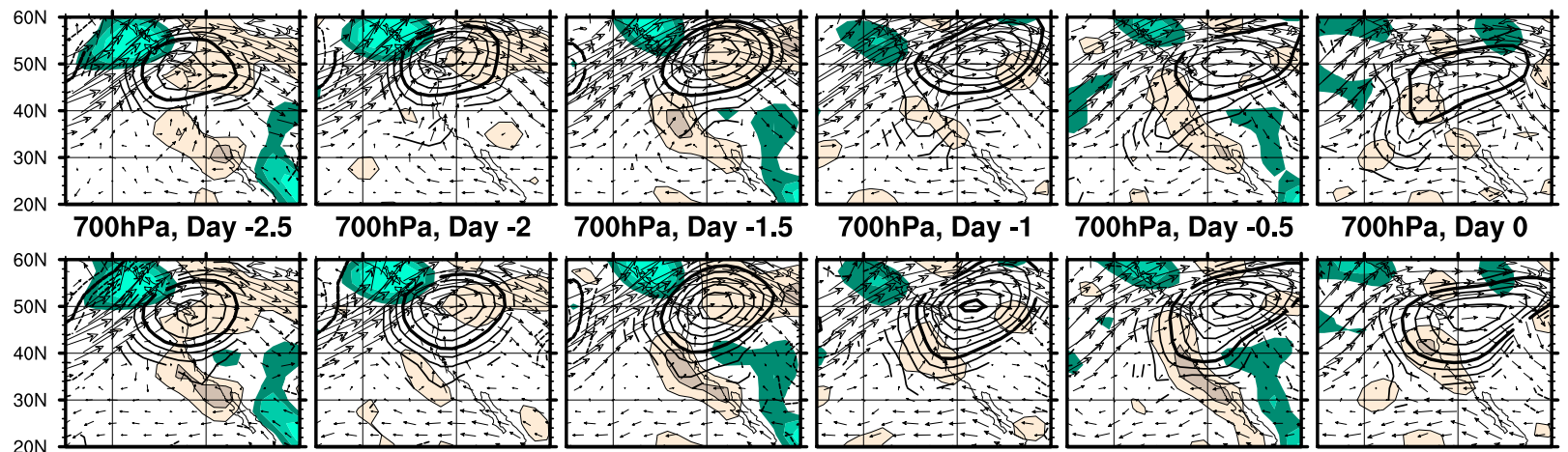

700hPa, Day 0

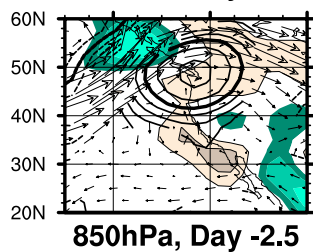

850hPa, Day -2
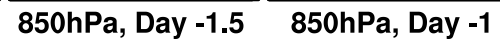

$850 \mathrm{hPa}$, Day -0.5
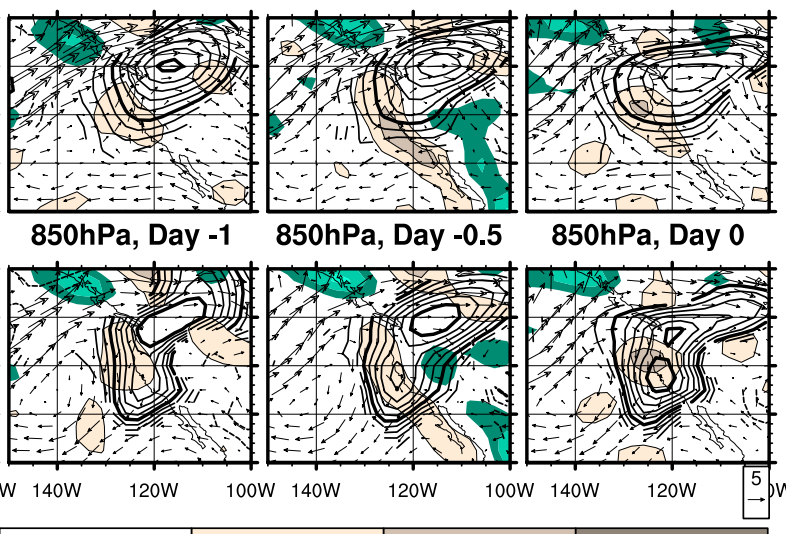

$850 \mathrm{hPa}$, Day 0

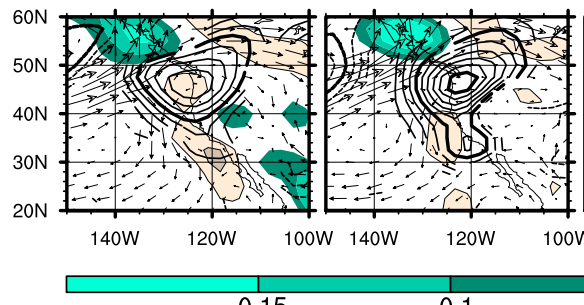

$-0.15$

$-0.1$

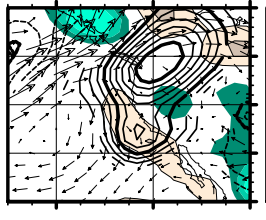

0

0.05

0.1

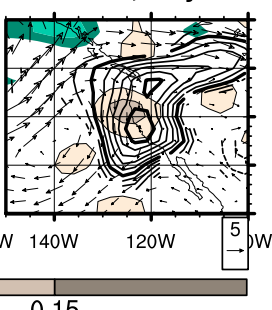

FIG. 6. As in Fig. 5, but for cluster 2.

heights were tested for each event. Figure 7 uses $850 \mathrm{hPa}$ for the starting level, and the paths descend to that level from pressure levels commonly between 600 and $800 \mathrm{hPa}$, with $500 \mathrm{hPa}$ being the maximum height. Trajectories in the second cluster on average have lower maximum heights than trajectories in the first cluster. Specifically, half of the events (5 out of 10) in cluster 2 have paths traced backward that stay below $700 \mathrm{hPa}$, while most events (10 out of 13) in cluster 1 have paths descending from elevations above $700 \mathrm{hPa}$. However, one of those three cluster 1 paths traced back to 700$800 \mathrm{hPa}$ had peak elevation of $600 \mathrm{hPa}$ before descending to the starting location at $850 \mathrm{hPa}$. Also, as anticipated, the two clusters show very different paths and origins zonally before onset. Paths in the first cluster (dashed paths) four days prior to onset often start west of $140^{\circ} \mathrm{W}$ (with three exceptions). In contrast, paths in the second cluster (solid paths) travel a short zonal distance and all trajectories remain east of $140^{\circ} \mathrm{W}$. Five paths in the second cluster start east of their final location. In the meridional plane, six paths in the second cluster reach the TA area from the region encompassing the Great Basin and the Mojave and Sonoran Deserts, while other paths arrive from the west and northeast or hardly move. In the first cluster the starting latitudes of paths are rather evenly spread. There appears to be a tendency for parcels in the first cluster to sink from a higher elevation when traveling from a higher latitude to reach the TA area.
Some differences in the total field LSMPs of the two clusters (Figs. 5 and 6) are worth emphasizing. In the first cluster, upstream of the west coast, strong westsouthwesterly flow extends across the domain at higher latitudes. Farther south, the upper-level winds weaken

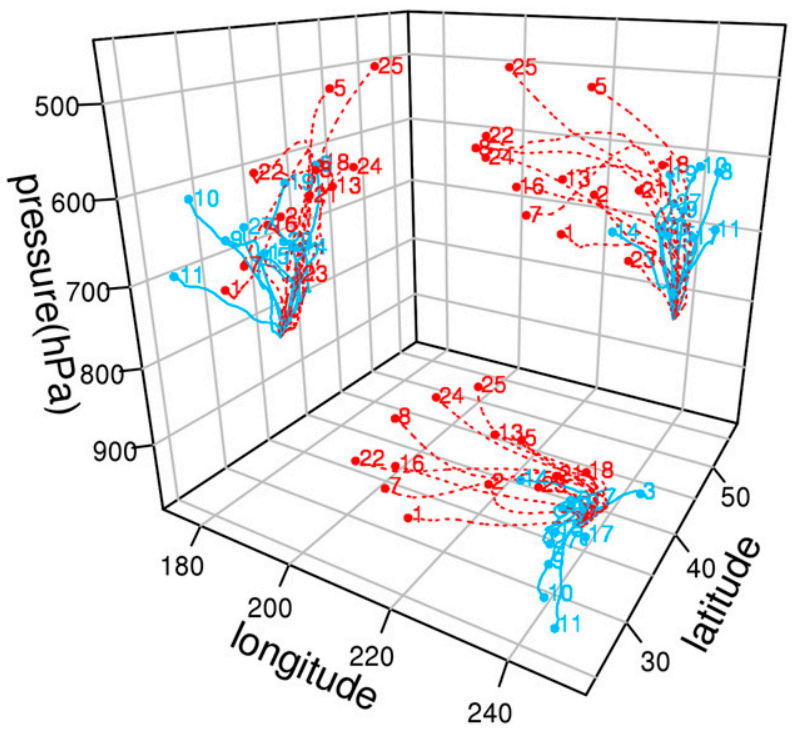

FIG. 7. Backward trajectories of the 28 events: 2D projections onto longitude-latitude, latitude-pressure, and longitude-pressure domain over 4 days prior to onset. The numbers refer to the event numbers specified in Table 1. Cluster 1 event trajectories use a red dotted line. Cluster 2 events use a blue solid line. Trajectories for mixed events are not drawn here. 
a)

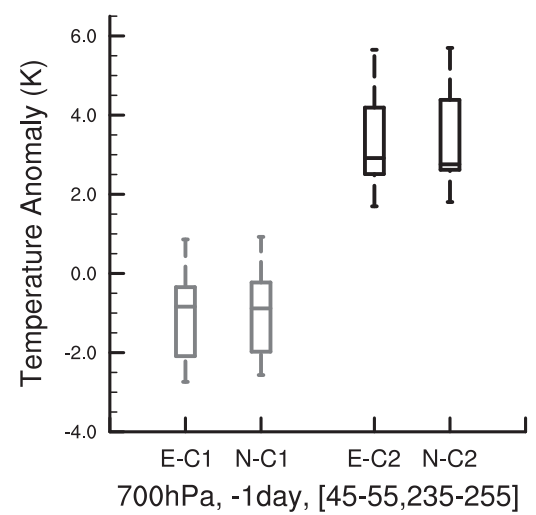

b)

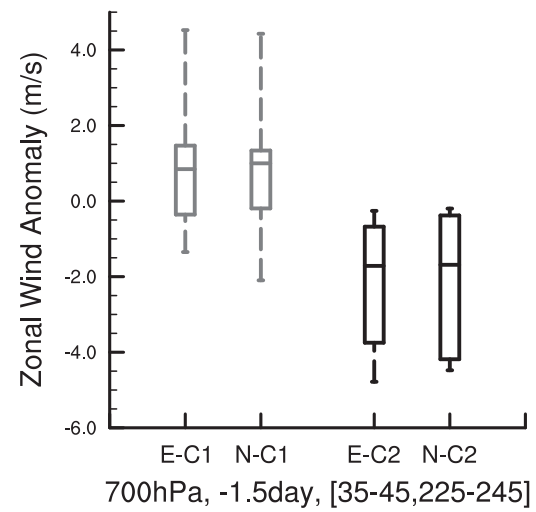

c)

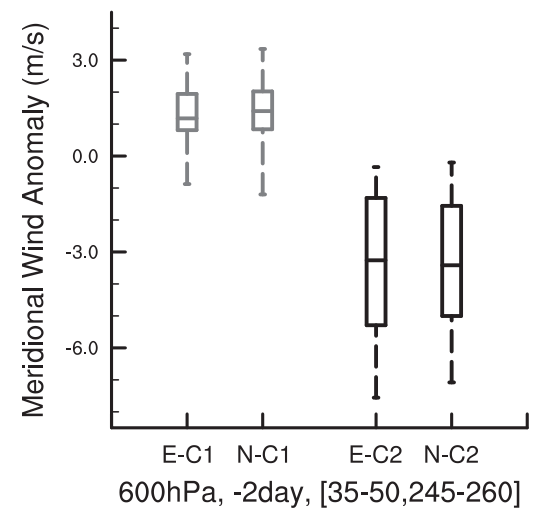

FIG. 8. Box-and-whisker plots comparing area average values for (a) temperature and (b) zonal and (c) meridional wind anomalies in selected regions, levels, and times for the indicated anomaly fields shown in Figs. 3 and 4. In each panel the left pair is for cluster 1 and the right pair is for cluster 2. In each pair the left member is calculated from ERA-Interim while the right member is calculated from R-1 data. Each box brackets the middle 50\% while the horizontal line within the box is the median value. Whiskers connect the highest and lowest values. Labels across the bottom of each panel indicate level, time before onset, north latitude range, and east longitude range. In (a)-(c), earlier times and regions in proximity to the TA region show consistency among cluster members but different cluster distributions.

and become more northwesterly as the temperature anomaly develops near the west coast. Development of the temperature anomaly in the TA region by onset time appears to be due to this long-lasting northwesterly flow that also continues to pass through a northwestsoutheast-oriented region of strong sinking off the west coast and paralleling the coast. In contrast, the flow in the second cluster is weaker all along the U.S. West Coast and has a southerly component at the West Coast (at 700 and $600 \mathrm{hPa}$ ) with evidence below $(850 \mathrm{hPa})$ of southerly or even southeasterly motion over land but northerlies offshore on the east side of the subtropical high. All paths are again passing through areas of sinking (although the anomalous sinking is generally far from the TA area except at onset) just upstream from where the temperature anomaly is growing; in cluster 2 that is on the southwest side of the preexisting northwestern U.S. anomaly. In the second cluster the total field shows a correspondence between the vectors on the southwest corner of the northwestern U.S. temperature anomaly that cross the broad area of enhanced sinking as the thermal anomaly expands on its southern side. In both clusters, the broad areas of sinking that paths traverse are more apparent in the daytime maps. Rising motions over the Rockies to the California Sierra Nevada during the afternoon are reduced by the anomalous sinking in both cases, although the timing relative to onset varies. At 600 and $700 \mathrm{hPa}$, high-latitude strong westerlies persist in both clusters. In the second cluster, the westerlies are shifted poleward owing to the preexisting northwestern U.S. thermal anomaly. The flow in the southeastern part of the domain also differs, having a stronger southeasterly flow component in cluster 2, consistent with some of the trajectories reaching the TA area coming from the southwestern deserts.

These motions and temperature differences leading up to onset are consistent within each cluster and distinct between clusters. Figure 8 shows box-and-whisker plots using R-1 and ERA-Interim over select regions and times. In Fig. 8a, the cold anomaly to the north in cluster 1 versus the warm preexisting hot anomaly in cluster 2 are obviously distinct at $700 \mathrm{hPa} 1$ day prior to onset. In Fig. 8b, 1.5 days before onset, the weak westerlies over the TA area are evident in cluster 1 , while cluster 2 events have net easterlies in the same region at $700 \mathrm{hPa}$. In Fig. 8c, 2 days prior to onset at midtropospheric levels to the northwest and partly encompassing the TA area, weak southerlies occur in cluster 1 but strong northerlies occur in cluster 2 . In all cases the two reanalyses have very similar distributions. For $850-\mathrm{hPa}$ temperature anomalies, a corresponding plot (not shown) over the TA region at onset finds complete overlap of values among the events and between both clusters for both reanalyses since event detection is basically based on near-surface standardized temperature anomalies.

\section{Dynamical differences driving two types of heat waves: WAF and jet stream}

The discussion above connects temperature anomalies, air motions, sinking, and strong adiabatic compressional warming. A key difference between the two types is that greater sinking over the TA region is 


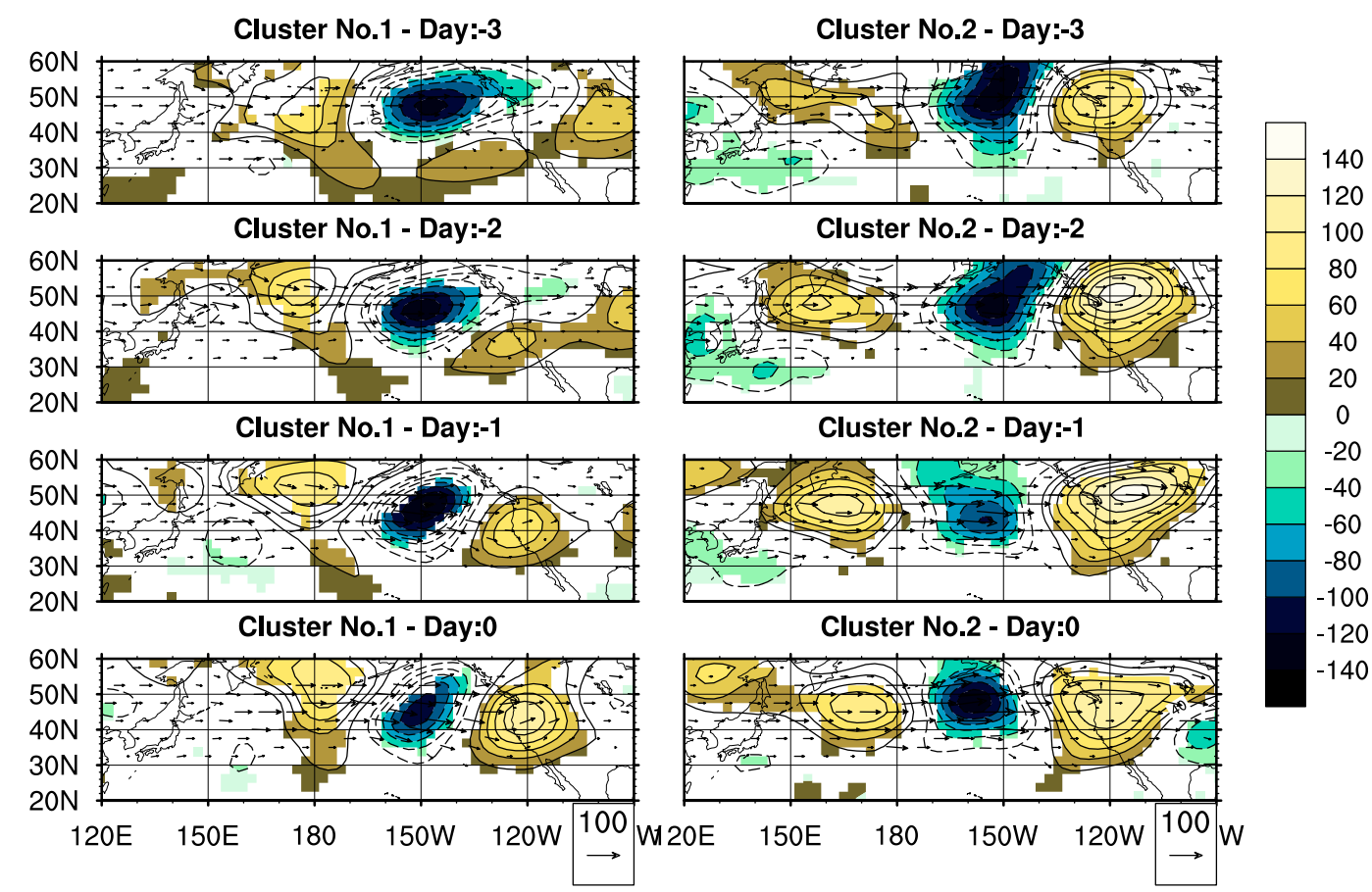

FIG. 9. Composite of geopotential height anomaly ( $\mathrm{m}$; contours) and total horizontal WAF $\left(\mathrm{m}^{2} \mathrm{~s}^{-2}\right.$; vectors) for two clusters at $500 \mathrm{hPa}$. Shading indicates significant area of geopotential height by plotting the grid points that have sign counts whose magnitude exceeds $1 / 3$. WAF is plotted only when either the zonal and meridional component has a sign count whose magnitude exceeds $1 / 3$. Contour interval is $20 \mathrm{~m}$.

required in cluster 1 since the air parcels are of maritime origin; in cluster 2 the parcels arrive from a region of preexisting warm air in the interior west. A more dynamical picture is presented here that reinforces the discussion above. In addition, the domain is expanded to provide a larger context for the heat wave development in these two clusters.

Since all events have high heat over the CCV, the strengths of the west coast ridge in the two clusters are similar at onset time. It is the differing evolutions prior to onset time that are of interest. Prior to onset, the two clusters have different wave patterns spanning the North Pacific in the composites of 500-hPa geopotential height anomalies (Fig. 9). The primary difference is the existence of a persistent, strong, west coast ridge in the second cluster versus development of that ridge in the first cluster. For the first cluster, an initially very weak ridge located west of California over the subtropical ocean strengthens and expands northward. Simultaneously, a North Pacific trough reduces its eastern extent, which implies the wave energy propagation toward the west coast. For the second cluster, positive height anomalies peak over the northwestern United States at 2-1.5-day lead. After that, the highest values in the ridge weaken, the area expands southward, and its center moves southwestward; concurrently, the North Pacific trough decreases in strength until lead day 1.5 and then increases again while drifting westward. From 2-day lead to onset, the zonal wavelength of the wave train is shorter in the first cluster than in the second cluster. The wave pattern is more zonally oriented in the second cluster, whereas the pattern follows more of a great circle route in the first cluster. Farther upstream, the LSMP in cluster number two shows a significant trough in the subtropics near the east coast of Asia (2.5-1.5-day lead). The trough near Asia may imply a connection to the tropics that is not further explored in this paper. As this near-Asia trough diminishes, the western North Pacific ridge strengthens and moves eastward while (as mentioned) the central North Pacific trough weakens and retreats slightly west. From 1-day lead, the central North Pacific trough becomes strong again while the two neighboring ridges become weak. These results imply that the energy propagation is not simple and more complicated in the second cluster.

Figure 9 also shows cluster mean WAF vectors for times prior to and including event onset. The WAFs differ between the clusters in ways consistent with the discussion above. In the first cluster, there are southeastward WAFs from the southern side of the midocean trough that become progressively stronger as onset is approached. The WAFs cross the Pacific with clear 
Cluster:1 - Day:-5

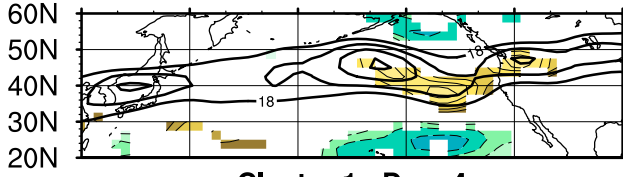

Cluster:1 - Day:-4

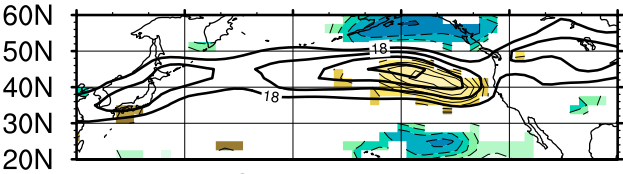

Cluster:1 - Day:-3

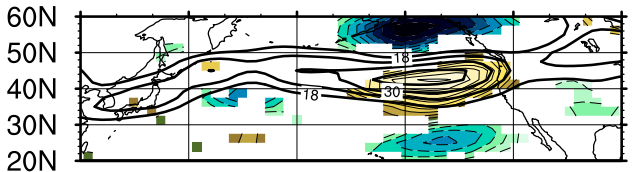

Cluster:1 - Day:-2

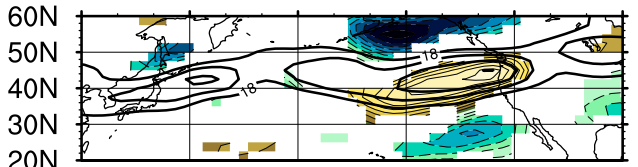

Cluster:1 - Day:-1

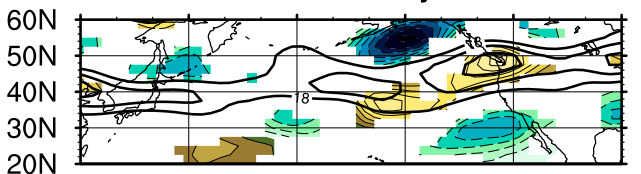

Cluster:1 - Day:0

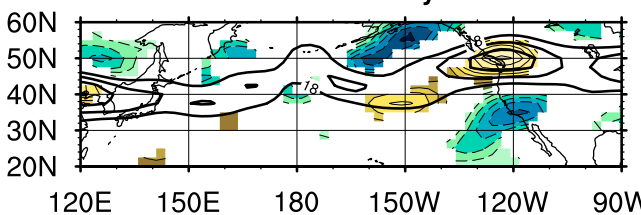

Cluster:2 - Day:-5

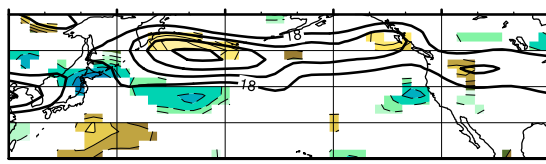

Cluster:2 - Day:-4

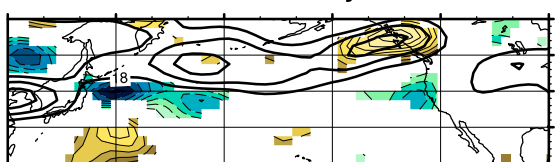

Cluster:2 - Day:-3

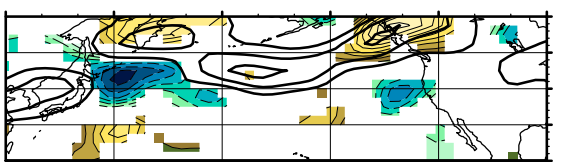

Cluster:2 - Day:-2

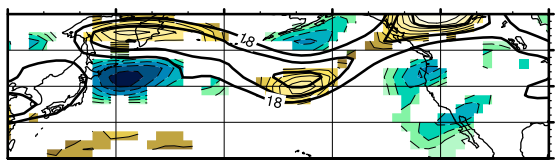

Cluster:2 - Day:-1

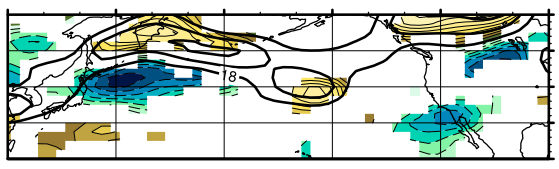

Cluster:2 - Day:0

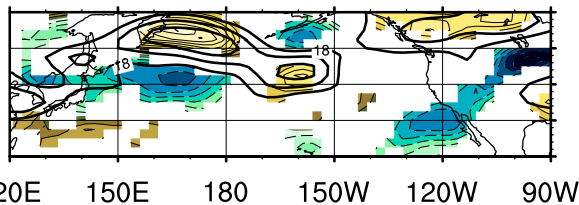

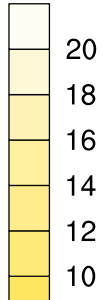

8

6

4

2

0

$-2$

$-4$

$-6$

$-8$

$-10$

$-12$

$-14$

$-16$

$-18$

$-20$

FIG. 10. Composite of total zonal winds (thick contours) and anomalous zonal winds (shading and thin contours) at $250 \mathrm{hPa}$. For the anomaly field, grid points are plotted only when the sign count has magnitude greater than $1 / 3$ of cluster member numbers. Contour interval is $2 \mathrm{~m} \mathrm{~s}^{-1}$ for anomaly field and $6 \mathrm{~m} \mathrm{~s}^{-1}$ for total field. The minimum contour of total field is $18 \mathrm{~m} \mathrm{~s}^{-1}$.

convergence in the eastern Pacific that is consistent with the building of the west coast ridge. In the second cluster, WAF vectors are somewhat stronger through most of the period. Close to onset time WAFs on the south side of the midocean trough amplify the southern side of the preexisting west coast ridge. Far upstream, the WAF off the Asian coast from the trough there builds the west Pacific ridge that is stronger and farther south in cluster 2 prior to onset. In cluster 1 , the south side of the western Pacific high grows later, closer to onset.

Given the different anomaly patterns in midtropospheric geopotential, one expects differences in the Pacific jet stream, as well. Figure 10 shows total zonal wind and zonal wind anomaly at $250 \mathrm{hPa}$, separately analyzed for the two clusters (shading for anomalies and darker contours for total fields). Anomaly winds at $250 \mathrm{hPa}$, the 500-hPa geopotential heights (Fig. 9), and the lower-level total horizontal winds (Figs. 5 and 6) all have anticyclonic flow over the North American west coast and farther upstream all have a midocean trough; hence, the LSMPs have equivalent barotropic structure as noted before (e.g., Grotjahn and Faure 2008). The equivalent barotropic structure of the wave train in each cluster is also confirmed from height anomaly patterns plotted at all significant levels in the troposphere (not shown).

In the first cluster, the northern dipole pair of wind anomalies in the eastern North Pacific expand and push the Pacific jet southward in the mid-Pacific and northward in the eastern North Pacific before event onset. The downstream expansion amplifies the total zonal component whose value peaks at a 3-day lead . Subsequently, the jet stream peak value diminishes while moving eastward, producing a clear deceleration region 
located offshore at latitudes $35^{\circ}-50^{\circ} \mathrm{N}$ that also moves eastward. From a simple momentum equation argument, this jet stream deceleration (jet streak exit) region could have southward ageostrophic motion. Ageostrophic northerlies at the jet exit coupled with little ageostrophic wind to the south that migrates eastward across the northern United States seems consistent with a similar migration of sinking seen in Fig. 5. Farther south, the easterly wind anomaly migrates northeastward toward the TA area as the thermal anomaly builds. In the second cluster westerly anomaly winds build the jet stream much farther north (western Canada) and easterly anomaly winds suppress it near the west coast of the United States (where the large temperature anomaly resides for days prior to onset). That thermal ridge over the west coast in both cases has easterly wind anomaly over Southern and Baja California, and this anomaly creates a small zonal variation of the zonal wind there. In a simple zonal momentum equation argument, a deceleration of easterly flow requires a southerly ageostrophic flow. Therefore, southerly ageostrophic winds could prevail in this region. Ageostrophic northerlies in the deceleration region of the Pacific jet coupled with ageostrophic southerlies where the North American jet accelerates (farther south) create upper-level convergence and sinking beneath as deduced from simple vorticity arguments (e.g., Grotjahn and Osman 2007) and as seen in Figs. 3 and 5 for the first cluster. That more southern jet location in the eastern Pacific seems consistent with the longer trajectories in the first cluster (although the jet is at a higher level than those paths). In the same manner, trajectories travel shorter distances in the second cluster, which seems consistent with a downstream weakening of the zonal winds along the U.S. West Coast.

On the opposite side of the Pacific, the westerly jet stream (Fig. 10) near the Asian coast curves much farther north in cluster 2, reflecting the stronger ridge (Fig. 9) in that region. In cluster 1 the jet stream is contiguous from the East Asian coast across the Pacific and into North America. In contrast, the connection to the East Asian jet becomes severed as onset approaches in cluster 2. A larger-amplitude wave train is present at this elevation for cluster 2, as well.

The LSMPs have a large-scale wave train, and we have been asked if these LSMPs are similar to wellknown teleconnection patterns. However, teleconnection patterns are based on longer-term variations in the circulation rather than the shorter-term fluctuations with extreme, highly episodic events. Moreover, most teleconnection patterns identified and cataloged by climatologists are based on analyses of the fluctuations in the wintertime flow. Nevertheless, we tested similarities to eight summer season teleconnection patterns (see http://www.cpc.ncep.noaa.gov/data/teledoc/telecontents. shtml) by calculating pattern projection coefficients for 10 days leading up to the event onset over the region $20^{\circ}-$ $60^{\circ} \mathrm{N}, 120^{\circ} \mathrm{E}-90^{\circ} \mathrm{W}$, where the LSMP wave train has large amplitude. It should be noticed that several of these teleconnection patterns have their largest amplitude outside the domain used in this calculation, so this test artificially magnifies the pattern projection for those teleconnection patterns.

For the NAO and Scandinavia patterns, averages of all events and each cluster mean and individual events show almost zero projection at the times tested (see Fig. S1 in the supplementary material). For the West Pacific, East Pacific-North Pacific, PNA, and East Atlantic-Western Russia patterns, projections vary slightly with time and between the two clusters. However, they are not significant since the values of the means are much smaller than the variation among events. For the East Atlantic pattern, three averaged projections of all events and two cluster members increase as time approaches the heat wave onset although the variation among events is much larger; even so, the projections have small values $(<0.15$ in all instances). Positive projection at the onset day might be considered significant since a majority of events have the same (positive) sign of projection coefficients. The reason for the (weak) positive projection is that the east Atlantic loading pattern has a strong west coast ridge over North America like the heat wave LSMPs do. For the PolarEurasia pattern, negative projection from 4 days prior to onset is common among the events. The Polar-Eurasia loading pattern has a zonal dipole over the high-latitude North Pacific, and this pattern is almost opposite to the pattern of heat wave LSMPs as shown in Fig. 9. Therefore, most events show negative projections. However, the main domains of the East Atlantic and PolarEurasia patterns are where the heat wave LSMPs are weak, and those domains are outside the Pacific sector used in this calculation. So the LSMPs' similarities in this sector seem to be little related to East Atlantic and Polar-Eurasia patterns. In summary, this projection analysis shows little relation between these heat wave LSMPs and most of the teleconnection patterns. However, this result does not preclude a teleconnection pattern from reinforcing the heat wave associated with the LSMPs.

\section{Summary and further discussion}

This study examines recent summer heat waves of the California Central Valley. This study focuses on three main issues: 1) spatiotemporal detection criteria of heat 
waves using normalized daily maximum surface temperatures of $15 \mathrm{CCV}$ NCDC stations, 2) validity of grouping $\mathrm{CCV}$ heat waves into two clusters based on noting differences in the LSMPs' evolution, and 3) examination of the LSMPs' properties with emphasis on the distinctly different formation of each cluster of heat waves.

Using normalized daily maximum surface temperature anomalies at $15 \mathrm{NCDC}$ stations, 28 heat wave events were identified when at least six stations surpass the $95 \%$ level for at least three days. After examination of three-dimensional backward trajectories and weather maps for each individual event, $k$-means clustering was applied to the merged anomalous field consisting of 700-hPa zonal wind (2-day lead), 600-hPa temperature (2-day lead), and 700-hPa temperature (1-day lead) over the domain $20^{\circ}-60^{\circ} \mathrm{N}, 150^{\circ}-100^{\circ} \mathrm{W}$. After testing several numbers of clusters $k$, two groups $(k=2)$ proved to be reasonable from the calculation of the intercluster distance metric. A projection analysis was also applied to check the reliability of $k$-means clustering results. A scatterplot of projection coefficients of individual events onto each of the two cluster composite fields finds two groups that are well separated with sufficient distance and events in a group to justify the clustering and to perform useful analyses. Among the 28 events during the 1977-2010 period, 5 events are mixed events not clearly associated with just one cluster; these events are excluded in the analysis. The final ensembles have 13 members in cluster 1 and 10 in cluster 2 .

Composite analyses are made of air temperature, horizontal wind, and omega for the two clusters at three vertical levels and on six lead times, including the onset time. These composite analyses focused upon a region centered near the Northern California coast, the TA area, which has been shown to be crucial for CCV heat waves (Grotjahn 2011). (A thermal low in sea level pressure there opposes a cooling sea breeze.) One difference between the two clusters of temperature anomalies is that the warm anomaly is slightly stronger in the second cluster than in the first cluster. The temperature anomaly has a southwestern lobe in the first cluster and a long northeastern lobe in the second cluster. In the first cluster, warm anomalies begin to form in the TA area, rapidly strengthening in the final 1.5 days before onset. The second cluster has a preexisting strong temperature anomaly to the north of the TA region; this anomaly becomes latitudinally elongated as a lobe develops southward, extending over the TA area during the 2.5 days prior to onset time. While the temperature anomaly increases over the TA area, the northern end of the preexisting anomaly migrates eastward, creating that lobe in cluster 2. The CCV heat wave follows the heat wave occurring in the northwestern United States for events in this second cluster. This link to the northwestern United States explains why Bachmann (2008) found that extremely hot days in Sacramento match dates of extremely hot days in Seattle better than in much closer Reno. After the peak of the northwestern heat wave, warm anomalies expand over the TA area by flow that passes through areas of enhanced sinking sometimes from south of the TA region but usually without traveling as far as air parcels in cluster 1.

In both clusters, although the pattern varies, the high temperatures result from compressional heating as horizontal winds transport sinking air to the TA region. Anomaly fields of sinking and horizontal motion help interpret the total fields of motion. The sinking adiabatically warms the lower troposphere and especially over land lowers the subsidence inversion. Solar heating rapidly raises surface station temperatures during the daylight hours because the surface heat flux is mixed into the shallower-than-usual layer below the subsidence inversion. In cluster 1 , the sinking anomaly is located to the northwest and northeast of the TA area where northerly and northeasterly anomaly winds occur. Upstream to the west, the wind anomalies are strongly southwesterly. When added to the long-term daily mean winds, these wind anomalies create a total wind that has strong westerlies upstream that turn to become northwesterly as the air encounters unusually strong sinking centered at or off the west coast of the United States. These northwesterlies are pointing toward the TA area, building the temperature anomaly rapidly there. Higher up, sinking over the TA area is consistent with ageostrophic wind convergence resulting from the Pacific jet exit region to the north and the North American jet entrance region to the south. In cluster 2 , the pattern is more complex. There is anomalous sinking to the east of the TA area and small velocities from the south and east. Total horizontal flow is quite mixed, as midtropospheric levels have sinking and southwesterlies on the north side of the TA area, while below ( $850 \mathrm{hPa}$ and below) there are northerlies in this area of sinking. On the south side of the TA area, there are southeasterly and easterly total winds, again passing through an area of sinking during the afternoon. The somewhat opposite directions that slow-moving, sinking air takes to build the temperature anomaly in the TA area contrasts with the simpler pattern of cluster 1 and shows up strikingly in air parcel trajectories.

Trajectories moving backward in time were calculated to trace the origin of air parcels arriving at onset in the TA area at $850 \mathrm{hPa}$. The two clusters show clear differences in the origins and traveling distance of these air 
parcels. Air parcels of the first cluster often travel eastward across much of the North Pacific, while air parcels of the second cluster are less consistent but include parcels moving out of the desert to the southeast. The far-western origins of most air parcels in the first cluster are consistent with the eastward extension of the Asian jet stream compared to the second cluster. Since the spatial resolution $\left(2.5^{\circ}\right.$ in latitude and longitude) of the R-1 data is somewhat coarse both horizontally and vertically, one may question the accuracy of trajectories and the robustness of this separation of trajectories between two clusters. This concern was checked by applying the trajectory calculation to the higher-resolution reanalysis of ERA-Interim (Dee et al. 2011). ERAInterim data have a $1^{\circ} \times 1^{\circ}$ resolution. Trajectories based on ERA-Interim data have similar primary properties: members consistently have longer traveling distances (eastward over the Pacific) in the first cluster while in cluster 2 trajectories again move slowly and come from various directions, including originating in the desert to the southeast. Again, the ERA-Interim paths pass through regions of sinking just prior to reaching low elevations in the TA area (not shown). Hence, all the main characteristics of the trajectories for these two clusters are not sensitive to the reanalysis data type and/or model resolution.

Temporal and spatial evolution of height anomalies and wave activity fluxes in the midtroposphere $(500 \mathrm{hPa})$ show the eastward energy propagation in both clusters. In the first cluster, the west coast ridge rapidly develops just prior to event onset along with the enhancement by southeastward directed WAF vectors off the west coast building internal energy (correspondingly, horizontal winds with the same orientation undergo strong sinking thereby building the warm anomaly in the TA area from compressional heating). The wave energy propagation across the North Pacific plays a crucial role in the formation of this first type of heat wave. Unlike the first cluster, height anomalies in the second cluster include a very strong preexisting wave train across the North $\mathrm{Pa}-$ cific, including a ridge that covers most of the northwestern United States (height anomaly centered at the U.S.-Canadian coastal border) and lasts three days or more before the CCV heat wave onset. As time nears the onset of the CCV heat wave, the northwestern ridge center elongates eastward on its northern end and also southward to encompass the TA area. Interestingly, maximum anomaly of this ridge weakens while the North Pacific trough amplifies. The invigorated midocean trough produces eastward WAF vectors on its southern side that enhance the southern expansion of the west coast ridge. Looking more broadly than the TA area, in the first cluster WAF is mainly directed east-southeastward in middle and high latitudes across the North Pacific with an equatorward component in the eastern Pacific. In the second cluster, by contrast, WAF is more zonal and directed eastward across the North Pacific over middle and subtropical latitudes for several days prior to onset, including a significant subtropical Pacific trough near the Asian coast. The wavelengths in the wave train are longer in the second cluster. In short, the patterns at the onset, at least locally to the CCV, look similar in all events studied, but these results reveal two very different origins of those onset patterns.

Acknowledgments. This research was funded in part by NSF Grant 1236681 and also supported by the USDA National Institute of Food and Agriculture, Hatch Project CA-D-LAW-4264-H. We also thank the anonymous peer reviewers for their helpful comments and feedback on the manuscript.

\section{REFERENCES}

Alexander, L. V., P. Uotila, and N. Nicholls, 2009: Influence of sea surface temperature variability on global temperature and precipitation extremes. J. Geophys. Res., 114, D18116, doi:10.1029/2009JD012301.

Bachmann, B. A., 2008: The spatial extent of California heat waves. M.S. thesis, Dept. of Land, Air and Water Resources, University of California, Davis, $163 \mathrm{pp}$.

Bilby, T., L. Baumgard, R. Collier, R. Zimbelman, and M. Rhoads, 2008: Heat stress effects on fertility: Consequences and possible solutions. Proc. Southwest Nutrition Conf., Tempe, AZ, University of Arizona, 177-193.

Bumbaco, K. A., K. D. Dello, and N. A. Bond, 2013: History of Pacific Northwest heat waves: Synoptic pattern and trends. J. Appl. Meteor. Climatol., 52, 1618-1631, doi:10.1175/ JAMC-D-12-094.1.

Cellitti, M. P., J. E. Walsh, R. M. Rauber, and D. H. Portis, 2006 : Extreme cold air outbreaks over the United States, the polar vortex, and the large-scale circulation. J. Geophys. Res., 111, D02114, doi:10.1029/2005JD006273.

Dee, D., and Coauthors, 2011: The ERA-Interim reanalysis: Configuration and performance of the data assimilation system. Quart. J. Roy. Meteor. Soc., 137, 553-597, doi:10.1002/qj.828.

Edmon, H., B. Hoskins, and M. McIntyre, 1980: Eliassen-Palm cross sections for the troposphere. J. Atmos. Sci., 37, 2600-2616, doi:10.1175/1520-0469(1980)037<2600:EPCSFT>2.0.CO;2.

Fischer, E. M., S. Seneviratne, P. Vidale, D. Lüthi, and C. Schär, 2007: Soil moisture-atmosphere interactions during the 2003 European summer heat wave. J. Climate, 20, 5081-5099, doi:10.1175/JCLI4288.1.

Gershunov, A., D. R. Cayan, and S. F. Iacobellis, 2009: The great 2006 heat wave over California and Nevada: Signal of an increasing trend. J. Climate, 22, 6181-6203, doi:10.1175/ 2009JCLI2465.1.

Grossman-Clarke, S., J. A. Zehnder, T. Loridan, and C. S. B. Grimmond, 2010: Contribution of land use changes to nearsurface air temperatures during recent summer extreme heat events in the Phoenix metropolitan area. J. Appl. Meteor. Climatol., 49, 1649-1664, doi:10.1175/2010JAMC2362.1. 
Grotjahn, R., 2011: Identifying extreme hottest days from large scale upper air data: A pilot scheme to find California Central Valley summertime maximum surface temperatures. Climate Dyn., 37, 587-604, doi:10.1007/s00382-011-0999-z.

_ 2013: Ability of CCSM4 to simulate California extreme heat conditions from evaluating simulations of the associated large scale upper air pattern. Climate Dyn., 41, 1187-1197, doi:10.1007/ s00382-013-1668-1.

_- and M. Osman, 2007: Remote weather associated with North Pacific subtropical sea level high properties. Int. J. Climatol., 27, 587-602, doi:10.1002/joc.1423.

_ , and G. Faure, 2008: Composite predictor maps of extraordinary weather events in the Sacramento, California, region. Wea. Forecasting, 23, 313-335, doi:10.1175/2007WAF2006055.1.

_- and Coauthors, 2015: North American extreme temperature events and related large-scale meteorological patterns: A review of statistical methods, dynamics, modeling, and trends. Climate Dyn., 1-34, doi:10.1007/s00382-015-2638-6.

Guirguis, K., A. Gershunov, R. Schwartz, and S. Bennett, 2011: Recent warm and cold daily winter temperature extremes in the Northern Hemisphere. Geophys. Res. Lett., 38, L17701, doi:10.1029/2011GL048762.

Higgins, R. W., A. Leetmaa, and V. E. Kousky, 2002: Relationships between climate variability and winter temperature extremes in the United States. J. Climate, 15, 1555-1572, doi:10.1175/ 1520-0442(2002)015<1555:RBCVAW $>2.0 . \mathrm{CO} ; 2$

Hirschi, M., and Coauthors, 2011: Observational evidence for soilmoisture impact on hot extremes in southeastern Europe. Nat. Geosci., 4, 17-21, doi:10.1038/ngeo1032.

Jeong, J.-H., C.-H. Ho, B.-M. Kim, and W.-T. Kwon, 2005: Influence of the Madden-Julian oscillation on wintertime surface air temperature and cold surges in East Asia. J. Geophys. Res., 110, D11104, doi:10.1029/2004JD005408.

Jones, T. S., and Coauthors, 1982: Morbidity and mortality associated with the July 1980 heat wave in St Louis and Kansas City, Mo. J. Amer. Med. Assoc., 247, 3327-3331, doi:10.1001/ jama.1982.03320490025030.

Kalnay, E., and Coauthors, 1996: The NCEP/NCAR 40-Year Reanalysis Project. Bull. Amer. Meteor. Soc., 77, 437-471, doi:10.1175/1520-0477(1996)077<0437:TNYRP>2.0.CO;2.

Lee, Y. Y., and R. X. Black, 2013: Boreal winter low-frequency variability in CMIP5 models. J. Geophys. Res., 118, 6891-6904, doi:10.1002/jgrd.50493.

Lim, Y. K., and S. D. Schubert, 2011: The impact of ENSO and the Arctic Oscillation on winter temperature extremes in the southeast United States. Geophys. Res. Lett., 38, L15706, doi:10.1029/2011GL048283.

Loikith, P. C., and A. J. Broccoli, 2012: Characteristics of observed atmospheric circulation patterns associated with temperature extremes over North America. J. Climate, 25, 7266-7281, doi:10.1175/JCLI-D-11-00709.1.

- and - 2014: The influence of recurrent modes of climate variability on the occurrence of winter and summer extreme temperatures over North America. J. Climate, 27, 1600-1618, doi:10.1175/JCLI-D-13-00068.1.
Meehl, G. A., C. Tebaldi, H. Teng, and T. C. Peterson, 2007: Current and future U.S. weather extremes and El Niño. Geophys. Res. Lett., 34, L20704, doi:10.1029/2007GL031027.

Nakamura, H., M. Nakamura, and J. L. Anderson, 1997: The role of high- and low-frequency dynamics in blocking formation. Mon. Wea. Rev., 125, 2074-2093, doi:10.1175/1520-0493(1997)125<2074: TROHAL $>2.0 . \mathrm{CO} ; 2$

Park, T.-W., C.-H. Ho, and S. Yang, 2011: Relationship between the Arctic Oscillation and cold surges over East Asia. J. Climate, 24, 68-83, doi:10.1175/2010JCLI3529.1.

Plumb, R. A., 1986: Three-dimensional propagation of transient quasi-geostrophic eddies and its relationship with the eddy forcing of the time-mean flow. J. Atmos. Sci., 43, 1657-1678, doi:10.1175/1520-0469(1986)043<1657:TDPOTQ>2.0.CO;2.

Seber, G. A., 2009: Multivariate Observations. Wiley Series in Probability and Statistics, Vol. 252, John Wiley and Sons, 686 pp.

Sillmann, J., M. Croci-Maspoli, M. Kallache, and R. W. Katz, 2011: Extreme cold winter temperatures in Europe under the influence of North Atlantic atmospheric blocking. J. Climate, 24, 5899-5913, doi:10.1175/2011JCLI4075.1.

Smith, A., and R. Katz, 2013: US billion-dollar weather and climate disasters: Data sources, trends, accuracy and biases. Nat. Hazards, 67, 387-410, doi:10.1007/s11069-013-0566-5.

Spath, H., 1985: Cluster Dissection and Analysis: Theory, FORTRAN Programs, Examples. Prentice-Hall, 226 pp.

Stefanon, M., F. D’Andrea, and P. Drobinski, 2012: Heatwave classification over Europe and the Mediterranean region. Environ. Res. Lett., 7, 014023, doi:10.1088/1748-9326/7/1/014023.

Takaya, K., and H. Nakamura, 2001: A formulation of a phaseindependent wave-activity flux for stationary and migratory quasigeostrophic eddies on a zonally varying basic flow. J. Atmos. Sci., 58, 608-627, doi:10.1175/1520-0469(2001)058<0608: AFOAPI $>2.0 . \mathrm{CO} ; 2$

Walsh, J. E., A. S. Phillips, D. H. Portis, and W. L. Chapman, 2001: Extreme cold outbreaks in the United States and Europe, 1948-99. J. Climate, 14, 2642-2658, doi:10.1175/1520-0442(2001)014<2642: ECOITU $>2.0 . \mathrm{CO} ; 2$

Wang, M., X. Yan, J. Liu, and X. Zhang, 2013: The contribution of urbanization to recent extreme heat events and a potential mitigation strategy in the Beijing-Tianjin-Hebei metropolitan area. Theor. Appl. Climatol., 114, 407-416, doi:10.1007/s00704-013-0852-x.

Westby, R. M., Y.-Y. Lee, and R. X. Black, 2013: Anomalous temperature regimes during the cool season: Long-term trends, low-frequency mode modulation, and representation in CMIP5 simulations. J. Climate, 26, 9061-9076, doi:10.1175/ JCLI-D-13-00003.1.

Wettstein, J. J., and L. O. Mearns, 2002: The influence of the North Atlantic-Arctic Oscillation on mean, variance, and extremes of temperature in the northeastern United States and Canada. J. Climate, 15, 3586-3600, doi:10.1175/1520-0442(2002)015<3586: TIOTNA $>2.0 . \mathrm{CO} ; 2$

Yin, D., M. L. Roderick, G. Leech, F. Sun, and Y. Huang, 2014: The contribution of reduction in evaporative cooling to higher surface air temperatures during drought. Geophys. Res. Lett., 41, 7891-7897, doi:10.1002/2014GL062039. 